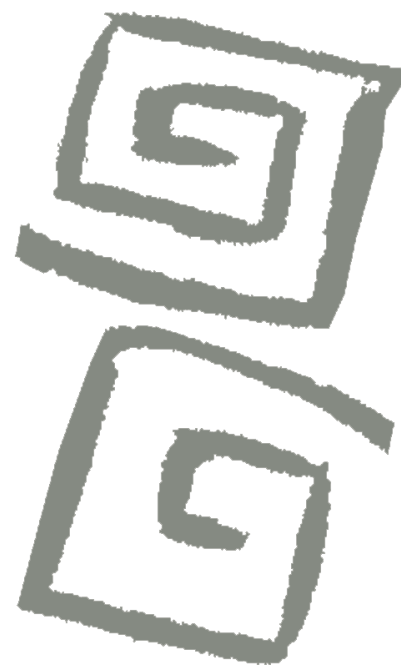

\title{
Entre la invisibilidad y el estigma: consumo de sustancias psicoactivas en mujeres embarazadas y puérperas de tres hospitales generales de Argentina
}

\author{
Between invisibility and stigma: consumption of \\ psychoactive substances among pregnant and \\ postpartum women at three Argentine general hospitals
}

Manuelita Diez ${ }^{1}$, María Pía Pawlowicz², Florencia Vissicchio ${ }^{3}$, Roxana Amendolaro ${ }^{4}$, Julia Carina Barla ${ }^{5}$, Analía Muñiz ${ }^{6}$, Leonardo Arrúa ${ }^{7}$

${ }^{1}$ Autora de correspondencia. Licenciada en Psicología. Becaria de investigación, Intercambios Asociación Civil, Ciudad Autónoma de Buenos Aires, Argentina. $\triangle$ iD

${ }^{2}$ Magíster en Salud y Ciencias Sociales. Coordinadora del área de investigación, Intercambios Asociación Civil, Ciudad Autónoma de Buenos Aires, Argentina. $\triangle$ iD

${ }^{3}$ Licenciada en Psicología. Becaria de investigación, Intercambios Asociación Civil, Ciudad Autónoma de Buenos Aires, Argentina. $\triangle$ (iD)

${ }^{4}$ Especialista en Políticas Públicas y Justicia de Género. Becaria de investigación, Departamento de Género, Municipio de Bariloche, Río Negro, Argentina. $\triangle$ (iD)

${ }^{5}$ Licenciada en Psicología. Jefa, Servicio de Salud Mental, Hospital Felipe Heras, Concordia, Entre Ríos, Argentina. $\triangle$ (ID)

${ }^{6}$ Licenciada en Trabajo Social. Trabajadora Social, Hospital Dr. Alberto Balestrini, La Matanza, Buenos Aires, Argentina. $\Delta$ iD

${ }^{7}$ Licenciado en Trabajo Social. Trabajador Social, Hospital Dr. Alberto Balestrini, La Matanza, Buenos Aires, Argentina. $\triangle$ iD
RESUMEN El consumo problemático de sustancias legales e ilegales en las mujeres embarazadas y puérperas es un tema de creciente preocupación sociosanitaria, que ha sido escasamente estudiado desde una perspectiva de género. Este artículo presenta los resultados obtenidos a partir de un estudio multicéntrico cualicuantitativo y transversal llevado a cabo entre mayo 2018 y junio 2019. El objetivo fue describir los patrones y representaciones del consumo de sustancias psicoactivas, así como el acceso a la atención en mujeres embarazadas y puérperas. La muestra fue intencional, conformada por 62 mujeres que asistían a hospitales generales de Bariloche, Concordia y La Matanza, que participaron de entrevistas semiestructuradas. Entre los resultados se destaca el tabú asociado a los consumos de sustancias psicoactivas en mujeres embarazadas y lactantes, la discriminación que estas mujeres experimentan en los servicios de salud y la falta de apoyo material que enfrentan las mujeres a la hora de realizar las tareas de cuidado, lo cual limita para ellas la posibilidad de cuidar de sí mismas.

PALABRAS CLAVES Trastornos Relacionados con Sustancias; Embarazo; Período Posparto; Salud Mental; Argentina.

ABSTRACT The problematic consumption of legal and illegal substances in pregnant and postpartum women is a growing socio-sanitary concern that has infrequently been studied from a gender perspective. This article presents the results of a multi-center, cross sectional study employing a mixed qualitative-quantitative approach that was conducted between May 2018 and June 2019. The aim of this research was to describe the patterns of psychoactive substance use as well as access to healthcare services among pregnant and postpartum women. Semi-structured interviews were conducted with a purposive sample of 62 women attending Bariloche, Concordia, and La Matanza General Hospitals. Results showed evidence of the taboo associated with psychoactive substance use among pregnant and postpartum women, the discrimination that these women experience in healthcare services, and their lack of material support, which makes it difficult for them to take care of themselves.

KEY WORDS Substances Related Disorders; Pregnancy; Postpartum Period; Mental Health; Argentina. 


\section{INTRODUCCIÓN}

\section{Panorama epidemiológico}

El consumo problemático de sustancias en mujeres embarazadas y puérperas es un tema de creciente preocupación sociosanitaria por diversos motivos, entre ellos, el aumento del consumo en esta población, el estigma social que recae sobre las madres usuarias de drogas y la desorientación que reportan los equipos de salud al abordar estas situaciones.

Se trata de un fenómeno que se constituye como un problema a nivel global. Datos recientes de organismos internacionales destacan que los patrones de consumo de drogas están cambiando: no solo la brecha de género asociada al uso de drogas se está cerrando en muchos países, sino que se señala el inicio del consumo de drogas a edades más tempranas ${ }^{(1,2)}$.

En Latinoamérica también se observa esta tendencia. Argentina y Uruguay presentan el nivel más alto de consumo de cocaína de la región $(1,6 \%)^{(2)}$, mientras que Chile, Brasil, Colombia y Venezuela exponen un rango intermedio de consumo de cocaína (del 0,5\% a $1,1 \%)$. Además, es notorio que las diferencias entre varones y mujeres son menores tanto en Argentina como Uruguay, países en los que hay alrededor de tres varones que consumen por cada mujer, en contraposición con países como Venezuela, donde la razón es de ocho varones por cada mujer y Colombia y Perú, donde es de seis varones por cada mujer. También se señala que las mujeres presentan un mayor uso no médico de psicofármacos -como tranquilizantes y estimulantes de prescripción controlada, drogas sintéticas y opioides-que los varones ${ }^{(2)}$.

Según los datos del último estudio nacional sobre consumos de sustancias en población general| ${ }^{(3)}$ se observó que, para las mujeres, entre 2010 y 2017, el consumo de alguna droga ilícita aumentó del 3,6\% al $8,3 \%$, observándose una duplicación en el consumo de cannabis $(4,7 \%$ a $13,9 \%)$ y una triplicación del consumo tanto de cocaína $(0,8 \%$ a $2,6 \%)$, como de alucinógenos $(0,4 \%$ a $1,5 \%)$ y de éxtasis $(0,3 \%$ a $1,1 \%)$.

Sin embargo, con relación a la información existente sobre el uso de drogas en mujeres embarazadas y puérperas, los datos son escasos y se centran principalmente sobre el consumo de sustancias legales, como tabaco y alcohol, y no sobre sustancias ilegales. En un estudio realizado en Uruguay y Argentina $^{(4)}$ cerca de la mitad de las 1.512 mujeres embarazadas que concurrieron a control prenatal en 12 hospitales públicos habían sido o eran fumadoras (44\% en Argentina y $53 \%$ en Uruguay). Durante el embarazo, el $11 \%$ de las mujeres en Argentina y el $18 \%$ en Uruguay continuaron fumando.

Un equipo de investigación del Consejo Nacional de Investigaciones Científicas y Técnicas (CONICET) con sede en la Universidad Nacional de Mar del Plata, que ha publicado diversos artículos referidos a los problemas de salud por consumo de alcohol en mujeres en edad reproductiva y gestantes ${ }^{(5)}$, en una de sus investigaciones realizada en la ciudad de Santa $\mathrm{Fe}^{(6)}$, señaló que el $75 \%$ de las 614 mujeres entrevistadas en dos centros perinatales manifestaron haber consumido alcohol durante la gestación, el 15\% reconoció haber tenido al menos un evento de consumo excesivo episódico (cinco tragos o más) durante la gestación y el 27,6\% durante el año anterior a la gestación. Esta omisión de las mujeres embarazadas a nivel de las estadísticas y de la construcción de datos constituye otro aspecto importante con relación a la problemática. De hecho, en el estudio nacional de la Secretaría de Políticas Integrales sobre Drogas de la Nación Argentina (SEDRONAR) de 2013, en la consulta a las salas de emergencia de 24 hospitales públicos del territorio nacional quedaron excluidas "todas las mujeres que asistieron por consultas obstétricas o de maternidad" por lo que no ofrece datos de esta población ${ }^{(7)}$. La invisibilidad aumenta, además, la vulnerabilidad de estas mujeres, configurándose así un círculo vicioso ${ }^{(8)}$. 


\section{Procesos de estigmatización, invisibilidad y vulnerabilidad}

A esta interacción entre invisibilidad y vulnerabilidad, la bibliografía sobre el tema agrega la cuestión de la estigmatización, ya que el campo de las drogas es uno de los ámbitos de la vida social que más está sujeto a prejuicios $^{(9,10)}$. Los procesos de estigmatización se manifiestan como actitudes hostiles hacia una persona que pertenece a un determinado grupo solo por el simple hecho de pertenecer a él y en función de cualidades negativas que se atribuyen a ese grupo de personas ${ }^{(11)}$. Estas actitudes se construyen alrededor de representaciones sociales, es decir, de una serie de creencias y conocimientos prácticos que son socialmente construidos e intersubjetivamente compartidos. Frente al miedo a ser juzgadas, estigmatizadas y rechazadas las mujeres ocultan sus consumos, interiorizan la visión negativa que de ellas tiene la sociedad y, consecuentemente, su autoestima tiende a ser más baja ${ }^{(12)}$.

Las mujeres, socializadas en el patriarcado, al consumir sustancias se alejan de las expectativas de su rol de género como mujeres $y$, por lo tanto, madres, protectoras, sumisas, que viven por y para los demás. Por este motivo, son rechazadas y doblemente estigmatizadas: por romper con el modelo de "identidad femenina" construida e idealizada que le fue asignada socialmente ${ }^{(13,14,15)}$ y por ser consumidoras de drogas. Si, además, las mujeres utilizan sustancias ilegales, el rechazo es mayor por su acercamiento a la ilegalidad ${ }^{(16)}$, y se vuelven objeto de una penalización moral y social por esa trasgresión ${ }^{(17,18)}$.

Sumado a ello, la mayor parte de los estudios continúa omitiendo la perspectiva de género como un factor decisivo en el análisis del problema ${ }^{(19)}$, por lo que los datos obtenidos se centran más en los efectos que el consumo tiene sobre las familias y allegados de las mujeres que sobre ellas mismas, proponiendo lecturas de asociación lineal que no integran las condiciones sociohistóricas de los problemas complejos ${ }^{(20)}$. Estos enfoques teóricos y metodológicos de análisis del fenómeno omiten el análisis de los mandatos patriarcales de "cuidado de otras personas" por sobre el "cuidado de sí" entre las mujeres. Como señalan Setién y Parga ${ }^{(21)}$, existen "estrategias biopolíticas de encausamiento de las conductas 'desviadas'" de las mujeres, que ejercen control sobre sus cuerpos, deseos y prácticas. Una de esas estrategias es la hipervisibilización de las usuarias de drogas cuando están cursando un embarazo y la consecuente estigmatización de sus prácticas en función de criterios morales de "buena" o "mala" madre. Esto introduce otro aspecto importante que cabe señalar aquí y es la problemática conceptualización de la maternidad como una experiencia natural, instintiva y universalizable, ya que no se trata de un hecho biológico sino de una construcción social $^{(22)}$. La percepción y representación de la maternidad varía según la generación, el lugar de origen y el espacio de socialización ${ }^{(23,24)}$.

Omitir la perspectiva de género implica, además, que las pautas de consumo de drogas se expliquen desde una perspectiva androcéntrica ${ }^{(25)}$. Romo Avilés y Camarotti ${ }^{(13)}$ sostienen que a pesar de que la pasta base de cocaína es una sustancia de graves efectos por su toxicidad, la forma y el contexto de consumo, las mujeres usuarias muestran la necesidad de "construir género" a través de su preocupación por su belleza, los efectos sobre el cuerpo y/o la maternidad, dando cuenta de cómo el género es performativo de sus acciones. "Adoptan un mundo masculino y en él incorporan estrategias femeninas para enfrentar este doble rechazo"(13).

En las investigaciones que estudian las representaciones sobre los consumos, se observa la tendencia, en consonancia con el paradigma punitivista, a resaltar principalmente los aspectos problemáticos del uso de sustancias, es decir, cuando este afecta negativamente la salud física o mental, las relaciones sociales y familiares, el trabajo/estudio, o las relaciones con la ley ${ }^{(26)}$, dejando de lado usos recreativos, religiosos que involucran diversos sentidos y beneficios para las personas, así como la dimensión del placer que puede involucrar esa práctica. De hecho, los consumos de sustancias, además de ser parte de las prácticas sociales al interior de los grupos 
convivientes, son significados de modos diversos según, entre otras dimensiones, los grupos sociales de pertenencia, las generaciones, la posición de género y de clase social, así como la configuración particular de los sentidos en tiempos y espacios determinados.

\section{Especificidades de las estrategias de atención de la salud}

Estas construcciones de los géneros también estructuran las estrategias de atención de los problemas de salud de las mujeres. Tal como lo plantea Menéndez ${ }^{(27)}$, estudiar el acceso a la salud supone considerar no solo al sistema formal de atención, sino también a las prácticas de autoatención que las personas y comunidades implementan para el cuidado de su salud. Estas prácticas, incluyen al conjunto de representaciones y de acciones que la población utiliza en forma autónoma para diagnosticar, explicar y atender los procesos que afectan su salud sin la intervención directa e intencional de las y los curadores profesionales ${ }^{(27)}$. Considerando el acceso a los servicios de salud, la accesibilidad se ha definido como el extremo más deseable de ingreso al sistema de salud, mientras que, en el otro extremo, se encuentran las barreras que representan la situación opuesta $^{(28)}$. La accesibilidad admite diversas dimensiones entre las que se reconocen: la organizacional, referida a las instancias burocráticas-administrativas; la geográfica, vinculada a las distancia a recorrer hasta la institución; la económica, que involucra los costos de los servicios; y la dimensión cultural, que refiere a los hábitos, prácticas, actitudes y creencias de las y los trabajadores de la salud y de las personas usuarias de los servicios ${ }^{(29)}$.

Entonces, cuando se analiza la posibilidad material de las mujeres de acceder a un tratamiento $\mathrm{y}$, luego, de poder sostenerlo, deben considerarse varias dimensiones. Tradicionalmente, se asigna a las mujeres la responsabilidad de las tareas domésticas y de cuidado de otras personas dependientes $y$, a su vez, cuentan con menor apoyo social. Esto dificulta el inicio y la continuidad de los tratamientos, dado que llevarlos adelante supone postergar las responsabilidades asignadas al rol de género ${ }^{(30)}$. Además, construcciones como el amor romántico también atentan contra la continuidad de los tratamientos, ya que ante la amenaza de ser abandonadas por sus parejas durante el proceso, deciden no consultar ${ }^{(31,32)}$. En este punto, se hace evidente que los consumos de sustancias psicoactivas en mujeres tienen costos sociales y familiares muy particulares y diferentes a los que atraviesan los varones ${ }^{(16)}$.

A partir de las dimensiones mencionados, en el abordaje de la problemática se pueden reconocer dos polos, que parecen opuestos pero cuyo resultado es el mismo para la población en cuestión. Tanto las investigaciones de corte estadístico como aquellas que proponen estrategias terapéuticas acerca de los consumos de sustancias psicoactivas, respecto de las mujeres embarazadas y puérperas oscilan entre dos posibilidades: o las tornan invisibles, excluyéndolas de los datos y los tratamientos, o las abordan sin reconocer las especificidades que el rol de subordinadas sociales imprime en las modalidades de consumo de las mujeres embarazadas y/o madres, recayendo sobre estas mujeres prejuicios y estigmas.

Desde esta perspectiva, el objetivo general del estudio en que se basa este artículo fue describir los patrones de consumo de sustancias psicoactivas, el acceso a la atención y los determinantes sociales de la salud en mujeres embarazadas y puérperas. En este artículo en particular, el trabajo se estructuró sobre la base de los siguientes interrogantes: ¿qué particularidades tienen los consumos de alcohol, tabaco, cannabis y cocaína entre las mujeres embarazadas y puérperas? ¿Qué representaciones sobre el consumo de sustancias y estrategias de atención de su salud tienen las mujeres cuando consumen sustancias psicoactivas durante el embarazo, el parto y el puerperio?

\section{METODOLOGÍA}

Se trató de un estudio multicéntrico exploratorio-descriptivo, cualicuantitativo y transver- 
sal. Fue realizado entre mayo 2018 y junio 2019, con el financiamiento de las becas de Salud Investiga de la Dirección de Investigación del Ministerio de Salud y Desarrollo Social de la Nación. Los hospitales que conformaron el ámbito de estudio fueron, el Hospital Zonal Dr. Ramón Carrillo, San Carlos de Bariloche, Río Negro; el Hospital Felipe Heras, Concordia, Entre Ríos; y el Hospital Dr. Alberto Balestrini, La Matanza, Buenos Aires.

La elección de las instituciones estuvo sujeta a criterios de accesibilidad y factibilidad. Asimismo, se buscó obtener una mayor riqueza de los datos ya que se trataba de una muestra, por un lado, homogénea al seleccionar el mismo tipo de efector de salud (hospitales generales provinciales) y, por otro, heterogénea, al ser de diferentes regiones del país.

El equipo de trabajo estuvo conformado por la coordinadora del estudio y siete profesionales de psicología y trabajo social, con experiencia en el tema, tanto en el área clínica como en investigación.

La muestra fue no probabilística, intencional y homogénea, conformada por 62 mujeres, mayores de 18 años, que consumieron alguna sustancia psicoactiva durante el embarazo y/o puerperio, que se atendieron en los hospitales participantes y que aceptaron firmar el consentimiento informado. El trabajo de campo se realizó entre julio de 2018 y enero de 2019, según lo dispuesto a partir del cronograma establecido con el ente financiador.

Se realizaron entrevistas semiestructuradas en las que se aplicó el mismo instrumento en las tres instituciones, que contenía preguntas cerradas y abiertas tomadas de módulos de instrumentos validados previamente. Si bien la integración de los módulos de varios instrumentos en uno resultó un tanto extenso, tuvo la ventaja de que al haber sido validados por agencias internacionales como la Organización Panamericana de la Salud (OPS), o agencias de gobierno nacionales, nos permitió contar con parámetros de interpretación a partir de estudios que muestran la distribución de los mismos indicadores a distintas escalas.
Las entrevistas se organizaron en las siguientes secciones:

a. Datos sociodemográficos: se realizaron preguntas cerradas acerca de la edad de la entrevistada, su lugar de residencia, el nivel de estudios alcanzado y la situación habitacional con relación a las personas con las vivía y a sus prácticas de consumo de sustancias.

b. Embarazo actual y previos: se indagó acerca de la planificación (o no) del embarazo, de la existencia de consultas obstétricas y de los servicios de salud a los que recurría para realizar el seguimiento del embarazo.

c. Puerperio y lactancia: se consultó sobre prácticas de lactancia, tanto exclusiva como mixta, y la alimentación de la o el lactante.

d. Problemas de salud: se preguntó acerca de la existencia de alguna de las siguientes enfermedades: sífilis, sífilis congénita, VIHsida, tuberculosis e ITS, y de las prácticas de cuidado que la mujer implementaba con relación a su propia salud. Tanto en esta categoría como en la anterior se tomaron como referencia preguntas del Sistema Informático Perinatal (SIP) de alcance nacional.

e. Consumo de sustancias: se aplicó la prueba ASSIST (alcohol, smoking, substance involvement screening test ${ }^{(33,34)}$ elaborado por la Organización Mundial de la Salud.

f. Violencia de género: las preguntas se basaron en el Estudio Nacional sobre Violencias contra la Mujer del Ministerio de Justicia y Derechos Humanos de la Nación ${ }^{(35)}$, que indaga la violencia de género a lo largo de la vida y en el último año, y quién la ejerció.

g. Apoyo social: se indagó sobre la cantidad de amistades íntimas o personas cercanas con las que las mujeres contaban para hablar de sus problemas, mediante una adaptación del cuestionario Medical Outcomes Study Social Support Survey (MOS-SSS) ${ }^{(36)}$. Se utilizaron los índices de Revilla et al. ${ }^{(37)}$, validados en Argentina por Rodríguez Espínola y Enrique ${ }^{(38)}$.

h. Representaciones sobre el consumo de sustancias y situaciones de discriminación: se trató de una serie de enunciados de elaboración propia sobre el grado de acuerdo a 
través de creencias sobre la peligrosidad de distintas drogas y de las posibles consecuencias para la salud. Para las preguntas sobre discriminación se partió de definiciones del Instituto Nacional contra la Discriminación, la Xenofobia y el Racismo (INADI) ${ }^{(39)}$.

i. Accesibilidad: se enumeró una lista de posibles barreras y dificultades de acceso a los servicios de salud, con respuestas ordinales prefijadas que se definieron con base a los resultados de un estudio sobre accesibilidad de los usuarios de drogas a los servicios públicos de salud en Buenos Aires y Rosario ${ }^{(29)}$.

j. Situación laboral: las preguntas de esta sección se basaron en la Tercera Encuesta Nacional de Factores de Riesgo para Enfermedades No Transmisibles ${ }^{(40)}$.

Las variables centrales se seleccionaron con base en el trabajo de operacionalización de las dimensiones de estudio y del análisis crítico de las ventajas y desventajas del uso de ciertas definiciones empíricas, a partir de la revisión de indicadores utilizados en instrumentos validados, de los que se contara con información epidemiológica nacional con la cual poder comparar. Por lo tanto, las variables principales bajo estudio para la unidad de análisis "mujeres embarazadas y puérperas" fueron: edad; mes de gestación o edad del hijo o de la hija, consumo de sustancias psicoactivas legales e ilegales; representaciones, información y experiencias del embarazo, parto y puerperio; configuración familiar; nivel educativo; situación ocupacional; redes sociales de apoyo; acceso a la atención de la salud; y estrategias de autoatención y de cuidados.

Las preguntas abiertas que buscaban recoger el relato textual sobre edad y modos de inicio, detalles sobre los efectos buscados y/o preocupaciones en torno a las experiencias de consumo fueron en su totalidad formuladas por el equipo de investigación. Los criterios que se tuvieron en cuenta para su selección fueron la adecuación con los objetivos planteados, las recomendaciones efectuadas por los cinco comités de ética intervinientes y la duración total de la entrevista.
El modo en que se abordaron las entrevistas semiestructuradas adquirió distintas particularidades según cada lugar y la forma de acceso. En Bariloche, implicó la realización de reuniones de presentación del proyecto a diferentes actores claves que luego gestionaron los contactos. En Concordia, dado que el Hospital Dr. Felipe Heras no contaba con servicio de maternidad y obstetricia se incluyó también a mujeres que acudían al Hospital General de Agudos Masvernat. En La Matanza, se establecieron contactos con distintos servicios del Hospital, hogares y paradores, y el Programa perteneciente al Sistema de Protección de Derechos de La Matanza. Se buscó establecer un día y horario para generar un espacio de confidencialidad. Se tomó nota de todo lo expresado por las mujeres. Solo fueron grabadas las entrevistas realizadas en La Matanza, por decisión de los/as entrevistadores/ as y con expreso consentimiento oral y escrito de las mujeres. Cada hospital aprobó la realización de la investigación por medio de sus autoridades y los Comité de Ética de los hospitales y provinciales evaluaron y aprobaron el proyecto de investigación. Intercambios Asociación Civil fue la institución coordinadora.

Para el análisis de los datos cuantitativos se utilizó el programa Statistical Package for the Social Sciences (SPSS) y se trianguló con el análisis cualitativo, partiendo del corpus del material textual que se segmentó y codificó para luego realizar análisis de contenido a partir del reconocimiento de regularidades y patrones identificados. Se procedió a combinar los criterios de derivación de las categorías centrales del estudio, enunciadas en los objetivos específicos, y los criterios de construcción de códigos emergentes de sentidos que se desplegaron en los materiales empíricos de tipo cualitativo.

\section{RESULTADOS}

Los resultados de la investigación se organizan aquí en cuatro partes: la primera es una breve presentación de las mujeres que participaron del estudio, la segunda se refiere a 
sus prácticas de consumo; una tercera parte aborda las representaciones sociales acerca del consumo y la maternidad, así como las experiencias de discriminación que atraviesan estas mujeres; y en el cuarto apartado se presentan los resultados relativos a la accesibilidad a los servicios de salud y las estrategias de autocuidado.

\section{Características de la muestra: ¿quiénes fueron las mujeres entrevistadas?}

Se entrevistó a 62 mujeres de La Matanza, Concordia y Bariloche, de las cuales 24 estaban atravesando el embarazo y 38 el puerperio, 48 se ubicaron en el rango etario de 18 y 29 años, y 14 de 30 y 39 años. Con relación al nivel educativo alcanzado, 6 mujeres iniciaron o completaron el nivel primario, mientras que 42 iniciaron o completaron el nivel secundario y 4 iniciaron o completaron el nivel terciario o universitario (Tabla 1).

Con respecto a los tipos de hogares, 57 entrevistadas convivían con otras personas, familiares o amistades, de las cuales 32 vivía en hogares nucleares y 25 en hogares extendidos o compuestos. Solo 3 vivían solas y otras 2 se encontraban en situación de calle.

En cuanto a la situación laboral, 12 mujeres se encontraban inactivas económicamente (no tenían trabajo ni buscaban), 24 estaban desocupadas (no tenía trabajo formal o informal pero lo buscaban), 24 habían trabajado la semana anterior a la entrevista, y 2 mujeres no explicitaron su situación laboral (Tabla 1).

De las 24 mujeres que habían trabajado la semana anterior a la entrevista, solo 3 contaban con un empleo formal, mientras que el resto refirió trabajar informalmente: 10 hacían changas (principalmente en trabajos asociados a la provisión de cuidado), 8 trabajaban por cuenta propia en emprendimientos sin contar con personas empleadas y 3 ejercían la prostitución (Tabla 1).

Entre las mujeres entrevistadas, 33 estaban en condición de gozar del período de 90 días de licencia por maternidad remunerada, de las cuales 4 cursaban las últimas cuatro semanas del embarazo y 29 atravesaban el puerperio
Tabla 1. Número y distribución porcentual de mujeres embarazadas y puérperas entrevistadas ( $N=62)$, según variables socioeconómicas. Ciudades de Bariloche, Concordia y La Matanza, Argentina, 2018-2019.

\begin{tabular}{|c|c|c|}
\hline Variables & $\mathrm{n}$ & $\%$ \\
\hline \multicolumn{3}{|l|}{ Estado } \\
\hline Embarazadas & 24 & 38,7 \\
\hline Puérperas & 38 & 61,3 \\
\hline \multicolumn{3}{|l|}{ Rango etario } \\
\hline 18 a 29 años & 48 & 77,4 \\
\hline 30 a 39 años & 14 & 22,6 \\
\hline \multicolumn{3}{|l|}{ Nivel educativo } \\
\hline Primario incompleto/ completo & 16 & 25,8 \\
\hline Secundario incompleto/completo & 42 & 67,7 \\
\hline Terciario o universitario completo/incompleto & 4 & 6,5 \\
\hline \multicolumn{3}{|l|}{ Tipo de hogares } \\
\hline Nuclear & 32 & 51,6 \\
\hline Extendidos o compuestos & 25 & 40,3 \\
\hline Vivían solas & 3 & 4,9 \\
\hline En situación de calle & 2 & 3,2 \\
\hline \multicolumn{3}{|l|}{ Situación laboral } \\
\hline Inactivas & 12 & 19,4 \\
\hline Desocupadas & 24 & 38,7 \\
\hline Empleo formal & 3 & 4,8 \\
\hline Empleo informal (changas) & 10 & 16,2 \\
\hline Empleo informal (cuentapropista) & 8 & 12,9 \\
\hline Empleo informal (en situación de prostitución) & 3 & 4,8 \\
\hline Sin información & 2 & 3,2 \\
\hline \multicolumn{3}{|l|}{ Condición de licencia por maternidad } \\
\hline \multicolumn{3}{|l|}{ En condición de licencia ${ }^{1}$} \\
\hline En relación de dependencia & 3 & 9,1 \\
\hline Por acuerdos en trabajo informal & 3 & 9,1 \\
\hline Sin licencia & 27 & 81,8 \\
\hline Sin condición de licencia & 29 & 46,7 \\
\hline \multicolumn{3}{|l|}{ Reciben subsidios del Estado } \\
\hline No reciben subsidios & 21 & 33,9 \\
\hline Asignación Universal por Hijo & 35 & 56,5 \\
\hline Seguro de desempleo & 1 & 1,6 \\
\hline Otros & 5 & 8,0 \\
\hline
\end{tabular}

Fuente: Elaboración propia.

'De las 33 mujeres en condición de licencia, 4 transitaban las últimas cuatro semanas de embarazo y 29 con hijos/hijas de hasta dos meses.

con hijos/hijas de hasta dos meses de vida. De estas 33 mujeres en condición de licencia, solo 6 efectivamente la gozaban: 3 de ellas como un derecho laboral por trabajar en relación de dependencia y otras 3 por acuerdos en su trabajo informal. Por otra parte, vale destacar que, de las 41 mujeres que afirmaron recibir subsidios del Estado, 35 percibían la Asignación Universal por Hijo, 4 señalaron que recibían "otros planes" y solo una estaba percibiendo un seguro de desempleo (Tabla 1). 
Las redes de pertenencia y el apoyo social con que cuentan las mujeres pueden constituirse en un factor protector, entendiendo como tal al conjunto de recursos del entorno que resultan favorecedores para el bienestar y que protegen a las personas de las adversidades que les presenta el medio ${ }^{(41)}$. La Tabla 2 muestra los valores obtenidos para las dimensiones de apoyo social, en la que se puede observar que los mayores niveles de apoyo se observan en la esfera afectiva ("alguien que te muestre amor y afecto", "alguien a quien amar y que te haga sentir querida"). Sin embargo, las entrevistadas percibieron menor nivel de apoyo de tipo material en actividades que requieren una ayuda activa: 12 contaban pocas veces o nunca con alguien que las ayude en tus tareas domésticas si estaban enfermas y 10 con alguien que las lleve al médico cuando lo necesiten. Respecto al apoyo emocional ("alguien con quien compartir tus temores y problemas más íntimos"), 10 mujeres refirieron que "pocas veces o nunca" contaban con alguien en este aspecto. Algunas entrevistadas, pese a referir que siempre o la mayoría de las veces contaban con apoyo, luego mencionaron que no recurrían a esas personas para compartir sus temores o problemas más íntimos.
Así, aunque el apoyo social total percibido es alto, cuando se desagregan sus dimensiones particulares, se dan con fuerzas desiguales, y las respuestas parecen señalar que el apoyo en las tareas domésticas y de cuidado tiende a ser menor que el apoyo emocional, afectivo o recreativo. Respecto del índice de apoyo social ${ }^{(37,38)}$ entre las mujeres entrevistadas, 43 contaban con un nivel de apoyo social total alto, 9 con apoyo medio y 10 con un nivel bajo.

\section{Patrones de consumo: diversidad en los usos de sustancias psicoactivas}

Los datos acerca de los consumos de alcohol, tabaco, cannabis y cocaína de las mujeres han sido organizados a partir de diferenciar tres situaciones de las entrevistadas: las embarazadas, las puérperas lactantes y las mujeres puérperas no lactantes (Tabla 3).

En el grupo de las 24 mujeres embarazadas se observó que, a lo largo de sus vidas, 22 habían usado alguna vez alcohol y 21 tabaco; además, 10 habían utilizado cannabis y 9 cocaína. En este mismo grupo, pero con relación a los últimos tres meses, 19 continuaban fumando tabaco y 16 alcohol. Acerca de las

Tabla 2. Número y distribución porcentual de las respuestas de las mujeres embarazadas y puérperas entrevistadas para cada dimensión de apoyo social (N=62). Ciudades de Bariloche, Concordia y La Matanza, Argentina, 2018-2019.

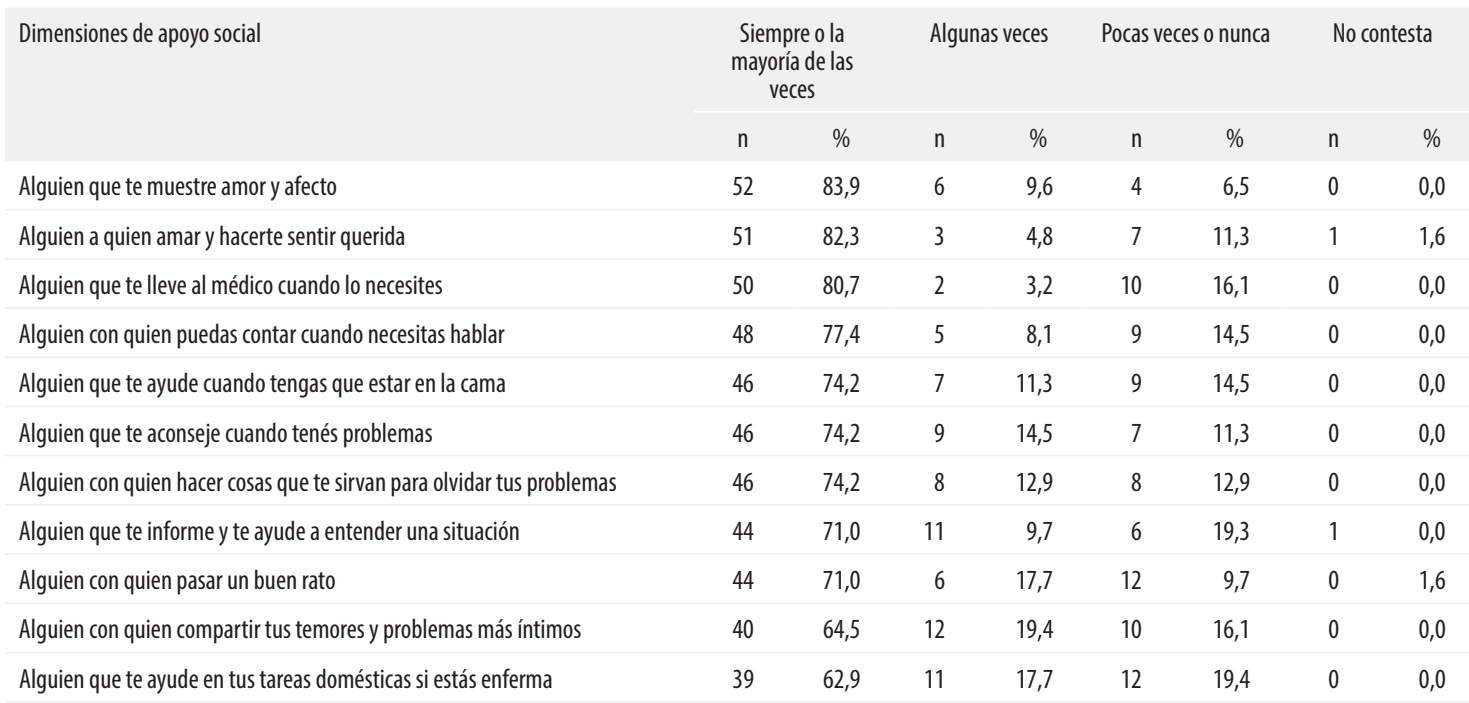

Fuente: Elaboración propia con base en la validación del cuestionario MOS de apoyo social de Revilla et al. ${ }^{(37)}$ validados en Argentina por Rodríguez Espínola y Enrique ${ }^{(38)}$. 
Tabla 3. Número y distribución porcentual de las mujeres embarazadas y puérperas lactantes y no lactantes entrevistadas ( $N=62$ ), según período de consumo y tipo de sustancias. Ciudades de Bariloche, Concordia y La Matanza, Argentina, 2018-2019.

\begin{tabular}{|c|c|c|c|c|c|c|c|c|}
\hline \multirow[t]{2}{*}{ Consumo de sustancias } & \multicolumn{2}{|c|}{$\begin{array}{l}\text { Embarazadas } \\
\qquad(n=24)\end{array}$} & \multicolumn{2}{|c|}{$\begin{array}{l}\text { Puérperas lactantes } \\
\qquad(n=33)\end{array}$} & \multicolumn{2}{|c|}{$\begin{array}{l}\text { Puérperas no } \\
\text { lactantes } \\
(n=5)\end{array}$} & \multicolumn{2}{|c|}{$\begin{array}{c}\text { Total } \\
(n=62)\end{array}$} \\
\hline & $\mathrm{n}$ & $\%$ & $\mathrm{n}$ & $\%$ & $\mathrm{n}$ & $\%$ & $\mathrm{n}$ & $\%$ \\
\hline \multicolumn{9}{|c|}{ Alguna vez en la vida consumió } \\
\hline Tabaco & 22 & 35,5 & 30 & 48,4 & 5 & 8,1 & 57 & 91,9 \\
\hline Alcohol & 21 & 33,9 & 33 & 53,2 & 3 & 4,8 & 57 & 91,9 \\
\hline Cannabis & 10 & 16,1 & 24 & 38,7 & 2 & 3,2 & 36 & 58,1 \\
\hline Cocaína & 9 & 14,5 & 16 & 25,8 & 3 & 4,8 & 28 & 45,2 \\
\hline \multicolumn{9}{|c|}{ En los últimos tres meses consumió } \\
\hline Tabaco & 19 & 30,6 & 17 & 27,4 & 5 & 8,1 & 41 & 66,1 \\
\hline Alcohol & 16 & 25,8 & 17 & 27,4 & 2 & 3,2 & 35 & 56,5 \\
\hline Cannabis & 7 & 11,3 & 7 & 11,3 & 0 & 0,0 & 14 & 22,6 \\
\hline Cocaína & 8 & 12,9 & 6 & 9,7 & 2 & 3,2 & 16 & 25,8 \\
\hline \multicolumn{9}{|c|}{ Durante el embarazo consumió } \\
\hline Tabaco & 19 & 30,6 & 24 & 38,7 & 5 & 8,1 & 48 & 77,4 \\
\hline Alcohol & 16 & 25,8 & 24 & 38,7 & 2 & 3,2 & 42 & 67,7 \\
\hline Cannabis & 7 & 11,3 & 15 & 24,2 & 1 & 1,6 & 23 & 37,1 \\
\hline Cocaína & 8 & 12,9 & 11 & 17,7 & 3 & 4,8 & 22 & 35,5 \\
\hline
\end{tabular}

sustancias de uso ilegal 7 consumían cannabis y 8 cocaína. Por lo tanto, los consumos predominantes en el embarazo para este grupo de mujeres fueron de alcohol y el tabaco.

En el grupo de las 33 mujeres puérperas lactantes se observó que a lo largo de su vida todas habían tomado alcohol alguna vez y 30 habían fumado tabaco; además, 24 habían usado cannabis y 16 cocaína. Por otro lado, en los últimos tres meses, entre estas mismas mujeres, 17 habían consumido tabaco, otras 17 habían tomado alcohol, 7 habían usado cannabis y 6 cocaína. Entre estas mujeres, 31 habían consumido alguna sustancia durante el embarazo, 24 habían fumado tabaco diariamente durante todo el embarazo, mientras que 24 consumieron alcohol. Respecto de las sustancias de uso ilegal, 15 habían fumado marihuana y 11 habían consumido cocaína (Tabla 3).

Por último, en el grupo de las 5 mujeres puérperas no lactantes (Tabla 3), se reportó que todas habían utilizado alguna vez tabaco, 3 habían bebido alcohol, 3 cocaína y 2 habían consumido cannabis. En los últimos tres meses todas estas mujeres continuaban usando tabaco y 2 alcohol. Estas 5 mujeres habían continuado fumando tabaco durante el embarazo, 2 de ellas además habían tomado alcohol y 2 cocaína.

Así es que, en función de estos datos, en el grupo de mujeres embarazadas y en el grupo de mujeres puérperas (lactantes y no lactantes), tanto para los consumos a lo largo de sus vidas como para aquellos que ocurrieron en los últimos tres meses y durante el embarazo, las cantidades mayores se dieron en relación al tabaco y al alcohol, lo cual coincide con los datos arrojados por el Estudio Nacional sobre Consumo de Sustancias Psicoactivas ${ }^{(3)}$.

Un factor que se asocia a los patrones de consumo es el hecho de convivir cotidianamente con otras personas usuarias de drogas. Sobre las 44 mujeres que informaron qué tipo de sustancias usaban las personas con las que convivían, en forma no excluyente, se distribuyeron de la siguiente manera: 36 alcohol, 29 tabaco, 9 cannabis, y en menor medida 5 pasta base de cocaína, y 4 cocaína. Además, sobre un total de 13 mujeres que 
Tabla 4. Número y distribución porcentual de las mujeres embarazadas y puérperas entrevistadas $(N=62)$ según uso y tipo de sustancias entre convivientes y situación de pareja. Ciudades de Bariloche, Concordia y La Matanza, Argentina, 2018-2019.

\begin{tabular}{lrr} 
Variables & $n$ & $\%$ \\
Uso de sustancias entre convivientes & & \\
\hline No convive con personas que usen sustancias & 14 & 22,6 \\
\hline Convive con personas que usen sustancias & 45 & 72,6 \\
\hline Sin información & 3 & 4,8 \\
\hline Sustancias consumidas por los convivientes & & \\
\hline Alcohol & 36 & 81,8 \\
\hline Tabaco & 29 & 65,9 \\
\hline Cannabis & 9 & 20,5 \\
\hline Pasta base de cocaína & 5 & 11,4 \\
\hline Cocaína & 4 & 9,1 \\
\hline Situación de pareja & & \\
\hline No tiene pareja & 22 & 35,5 \\
\hline Tiene pareja no conviviente & 13 & 20,9 \\
\hline Tiene pareja conviviente & 27 & 43,6 \\
\hline Fuente: Elaboración propia. & & \\
\hline Respuestas múltiples sobre 44 mujeres. & & \\
\hline
\end{tabular}

se encontraban en pareja al momento de la entrevista pero que no convivían con ellas, 8 afirmaron que su pareja consumía alguna sustancia (Tabla 4).

Con relación a los sentidos que las mujeres otorgan a sus consumos de sustancias $-y$ en particular con respecto a sus primeras experiencias- gran parte de las mujeres entrevistadas relató haberlas tenido en compañía de amistades, en situaciones recreativas. Salidas nocturnas, recitales y fiestas fueron los contextos de iniciación mencionados. Algunas también refirieron que las drogas les permitían desconectarse de situaciones problemáticas.

Entre las preocupaciones que experimentaron por consumir durante el embarazo, muchas mujeres mencionaron las consecuencias que el propio consumo tendría sobre la salud física de sus hijas o hijos por nacer y, en menor medida, el temor de que el consumo podría ocasionar situaciones de prematurez.

Cabe destacar que algunas entrevistadas se refirieron al placer, mencionando la sensación de calma y relajación que las sustancias les aportan y la atención que reciben de sus allegados a partir del hecho de consumir. Solo una de las entrevistadas afirmó que nada del consumo le provocaba placer.
Me gusta consumir tabaco porque me saca el stress, la marihuana me relaja. (29 años, puérpera, La Matanza)

...era cuando salía, todos tomaban... me divierte. (19 años, puérpera, Concordia) ...el "cigarro" me tranquiliza. El alcohol la divierte (24 años, embarazada, Bariloche)

\section{Representaciones sociales y discriminación: el estigma de "las madres que consumen"}

Las mujeres entrevistadas adhirieron mayoritariamente a aquellas representaciones que connotan juicios de valor negativos respecto a las mujeres que, siendo madres, consumen sustancias psicoactivas. El hecho de que las entrevistadas adhieran a este tipo de representaciones resulta en una visualización negativa de ellas mismas (culpa, reproches), en el temor a ser denunciadas, a no recibir atención en los servicios de salud y a ser discriminadas (castigo). Con relación a este último aspecto, 32 entrevistadas afirmaron haberse sentido discriminadas alguna vez en sus vidas. Entre ellas, los lugares de discriminación más frecuentemente referidos fueron, de modo no excluyente: las instituciones de salud, la sociedad en general (la calle, el barrio ó boliches), las instituciones educativas, el trabajo y la familia (Tabla 5).

En los ámbitos señalados, las mujeres indicaron haber sido tratadas diferencial y negativamente por sus características personales $^{(39)}$. La característica que más se destacó fue la discriminación asociada a la categoría de situación socioeconómica de pobreza ${ }^{(39)}$, que incluye no solo a las mujeres en situación de desocupación, sino también a aquellas mujeres subocupadas.

[Me sentí discriminada por...] Un médico me dijo que a "negros" no atendía... pedí que me atendiera otra persona y ahí sí fui bien atendida. (23 años, puérpera, Bariloche) 
Tabla 5. Número y distribución porcentual de las mujeres embarazadas y puérperas entrevistadas ( $N=62)$, según vivencias de discriminación. Ciudades de Bariloche, Concordia y La Matanza, Argentina, 2018-2019.

\begin{tabular}{lcc}
$\begin{array}{l}\text { Vivencias de discriminación } \\
\text { Alguna vez se sintió discriminada }\end{array}$ & n \\
\hline Sí & 32 & 51,6 \\
\hline No & 29 & 46,8 \\
\hline Sin información & 1 & 1,6 \\
\hline Ámbito donde se sintió discriminada' & & \\
\hline En instituciones de salud & 11 & 34,4 \\
\hline "En la calle, el barrio o boliches" & 10 & 31,2 \\
\hline En instituciones educativas & 7 & 21,9 \\
\hline En el trabajo & 3 & 9,4 \\
\hline En la familia & 3 & 9,4 \\
\hline $\begin{array}{l}\text { Fuente: Elaboración propia. } \\
\text { 'Respuestas múltiples sobre } 32 \text { mujeres. }\end{array}$ & & \\
\hline
\end{tabular}

Por la piel [lesiones por escabiosis]... y porque trabajo con la basura... (19 años, puérpera, Concordia)

Por las drogas, porque soy madre soltera, porque me tuve que prostituir para darle de comer a mis hijos. (18 años, embarazada, Concordia)

Otras características por las que mencionan haber sido discriminadas fueron la edad, los caracteres fenotípicos como el color de piel y la condición de migrantes.

[Me discriminaron] porque era menor de edad, me hacían más estudios a mí que a otras mujeres cuando tuve mi primer hijo en el Piñero. (26 años, puérpera, La Matanza)

Por la falta de DNI argentino, al momento del parto me dijeron: "estas extranjeras". (39 años, puérpera, La Matanza)

Me sentí humillada por mi aspecto, me tratan mal por tener la piel oscura. (34 años, puérpera, Bariloche)

La discriminación de género también fue destacada por las mujeres. Nos referimos a todas aquellas construcciones que asignan determinados roles y atributos socioculturales a partir del sexo biológico y que convierten la diferencia sexual en desigualdad social ${ }^{(39)}$.

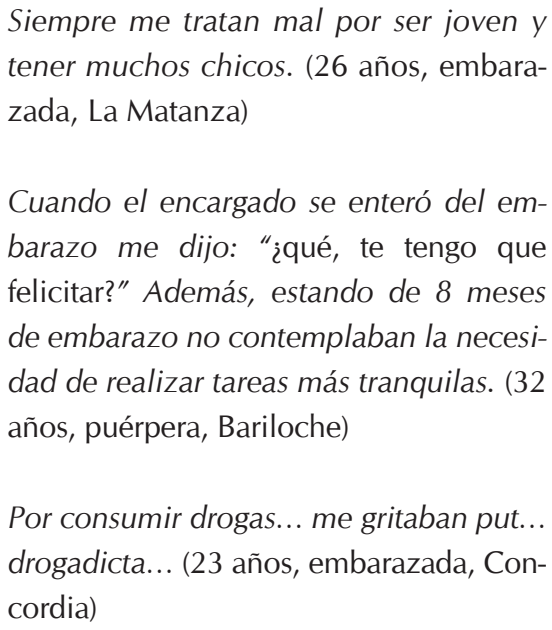

Algunas mujeres refirieron haber sido víctimas de tratos despectivos por parte del personal de salud por la doble condición de encontrarse en situación de embarazo o puerperio y ser usuarias de drogas.

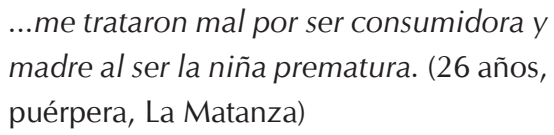

...por no hacerme los controles (obstétricos), en el hospital todos los médicos me tratan mal. (18 años, puérpera, Concordia)

Sin embargo, cabe destacar que, pese a que 50 mujeres respondieron estar "totalmente de acuerdo/de acuerdo" con que "Las mujeres embarazadas suelen ocultar su consumo por temor a ser juzgadas y discriminadas", a su vez, 31 afirmaron estar de "totalmente de acuerdo/de acuerdo" con que "Las mujeres embarazadas suelen ocultar su consumo por temor a no ser atendidas en los servicios de salud" (Tabla 6). Así, podría inferirse que, en muchas oportunidades, la situación de discriminación queda encubierta en el ocultamiento del consumo.

Con relación al trato recibido por las mujeres de parte de las y los agentes de salud al 
Tabla 6. Número y distribución porcentual de las respuestas de las mujeres embarazadas y puérperas entrevistadas $(\mathrm{N}=62)$, acerca de las representaciones sobre el consumo de sustancias. Ciudades de Bariloche, Concordia y La Matanza, Argentina, 2018-2019.

\begin{tabular}{|c|c|c|c|c|c|c|c|c|}
\hline \multirow[t]{2}{*}{ Representaciones sobre el consumo de sustancias } & \multicolumn{2}{|c|}{$\begin{array}{l}\text { Totalmente de } \\
\text { acuerdo/ de } \\
\text { acuerdo }\end{array}$} & \multicolumn{2}{|c|}{$\begin{array}{l}\text { Medianamente de } \\
\text { acuerdo }\end{array}$} & \multicolumn{2}{|c|}{$\begin{array}{l}\text { En desacuerdo/ } \\
\text { totalmente en } \\
\text { desacuerdo }\end{array}$} & \multicolumn{2}{|c|}{ No Contesta } \\
\hline & $\mathrm{n}$ & $\%$ & $\mathrm{n}$ & $\%$ & $n$ & $\%$ & $\mathrm{n}$ & $\%$ \\
\hline $\begin{array}{l}\text { Suele estar peor visto que una madre use drogas a que un padre } \\
\text { lo haga }\end{array}$ & 54 & 87,1 & 4 & 6,5 & 4 & 6,4 & 0 & 0,0 \\
\hline $\begin{array}{l}\text { Las mujeres embarazadas suelen ocultar su consumo por temor a } \\
\text { ser juzgadas y discriminadas }\end{array}$ & 50 & 80,7 & 1 & 1,6 & 9 & 14,5 & 2 & 3,2 \\
\hline $\begin{array}{l}\text { Las mujeres embarazadas suelen ocultar su consumo por temor a } \\
\text { ser denunciadas }\end{array}$ & 49 & 79,1 & 5 & 8,1 & 8 & 12,8 & 0 & 0,0 \\
\hline $\begin{array}{l}\text { La gente suele pensar que sos mala madre si usas drogas cuando } \\
\text { estas embarazada, amamantando o tenés un bebe }\end{array}$ & 48 & 77,4 & 10 & 16,1 & 4 & 6,5 & 0 & 0,0 \\
\hline $\begin{array}{l}\text { Las mujeres embarazadas suelen ocultar su consumo por temor a } \\
\text { perder a sus hijos }\end{array}$ & 47 & 75,8 & 4 & 6,5 & 11 & 17,7 & 0 & 0,0 \\
\hline $\begin{array}{l}\text { Las mujeres embarazadas suelen ocultar su consumo por sentir } \\
\text { culpa y vergüenza }\end{array}$ & 43 & 69,3 & 8 & 12,9 & 11 & 17,8 & 0 & 0,0 \\
\hline Una mujer que usa drogas suele ser vista como mala madre & 41 & 66,1 & 9 & 14,6 & 11 & 17,7 & 1 & 1,6 \\
\hline $\begin{array}{l}\text { Las personas suelen creer que las mujeres embarazadas que } \\
\text { consumen pasta base dañan más su salud que las que consumen } \\
\text { cocaína }\end{array}$ & 40 & 64,5 & 4 & 6,5 & 16 & 25,8 & 2 & 3,2 \\
\hline Tomar alcohol en pequeñas cantidades no afecta al embarazo & 32 & 51,6 & 10 & 16,1 & 19 & 30,7 & 1 & 1,6 \\
\hline $\begin{array}{l}\text { Las mujeres embarazadas suelen ocultar su consumo por temor a } \\
\text { no ser atendidas en los servicios de salud }\end{array}$ & 31 & 50,0 & 6 & 9,7 & 24 & 38,7 & 1 & 1,6 \\
\hline Cuando estás drogada te olvidás de usar forro & 31 & 50,0 & 8 & 12,9 & 19 & 30,6 & 4 & 6,5 \\
\hline $\begin{array}{l}\text { La gente suele pensar que consumir tabaco durante el embarazo } \\
\text { hace menos daño que consumir marihuana }\end{array}$ & 26 & 41,9 & 12 & 19,4 & 24 & 38,7 & 0 & 0,0 \\
\hline Fumar no afecta al embarazo & 22 & 35,5 & 4 & 6,5 & 34 & 54,8 & 2 & 3,2 \\
\hline $\begin{array}{l}\text { Consumir psicofármacos durante el embarazo no es tan grave } \\
\text { como consumir otras drogas }\end{array}$ & 14 & 22,6 & 16 & 25,8 & 32 & 51,6 & 0 & 0,0 \\
\hline
\end{tabular}

momento de atender sus embarazos, partos y puerperios, algunas de las entrevistadas refirieron haber sido, además de discriminadas, víctimas de violencia obstétrica. En esos relatos mencionan con cierta naturalización, sobre todo, la falta de acceso y comprensión de la información, insuficiente acompañamiento, escasa consideración del momento vital que atravesaban y prolongación innecesaria del dolor, entre otros aspectos. Algunas mujeres manifestaron "esperar hasta lo último", es decir el parto, para acercarse al hospital a fin de evitar maltratos, a pesar de no haber tenido controles durante el embarazo en varios casos. Otras dieron cuenta de cierto grado de insensibilidad por parte de agentes sanitarios ante el dolor de las mujeres. Relataron situaciones diversas y variadas de angustia y desorientación en las que no entendían lo que sucedía en ciertos procedimientos como, por ejemplo, ante un aborto espontáneo o una muerte fetal, o situaciones en las que las mujeres consideraron que no les permitieron tomar parte en la decisión sobre el tipo de parto, vulnerando así sus derechos.

\section{Estrategias de atención de la salud}

Continuando con el vínculo con los servicios de salud, se presentan los resultados acerca de la accesibilidad, cuyo detalle puede observarse en la Tabla 7 . Se destaca que 43 mujeres afirmaron que siempre o casi siempre debían "esperar mucho hasta ser atendidas", lo que constituye una de las mayores barreras 
Tabla 7. Número y distribución porcentual de las respuestas de las mujeres embarazadas y puérperas entrevistadas $(\mathrm{N}=62)$, sobre dimensiones de la accesibilidad a los servicios de salud. Ciudades de Bariloche, Concordia y La Matanza, Argentina, 2018-2019.

\begin{tabular}{|c|c|c|c|c|c|c|c|c|}
\hline \multirow[t]{2}{*}{ Accesibilidad a los servicios de salud } & \multicolumn{2}{|c|}{$\begin{array}{l}\text { Siempre o casi } \\
\text { siempre }\end{array}$} & \multicolumn{2}{|c|}{ La mitad de las veces } & \multicolumn{2}{|c|}{ Casi nunca o nunca } & \multicolumn{2}{|c|}{ No contesta } \\
\hline & $\mathrm{n}$ & $\%$ & $\mathrm{n}$ & $\%$ & $\mathrm{n}$ & $\%$ & $\mathrm{n}$ & $\%$ \\
\hline Esperar mucho hasta ser atendida & 43 & 69,4 & 10 & 16,1 & 8 & 12,9 & 1 & 1,6 \\
\hline Que no haya turnos & 33 & 53,2 & 17 & 27,4 & 11 & 17,8 & 1 & 1,6 \\
\hline Que te den turno muy a largo plazo & 33 & 53,2 & 17 & 27,4 & 11 & 17,8 & 1 & 1,6 \\
\hline Que el/la profesional te atienda muy rápido & 30 & 48,4 & 18 & 29,0 & 13 & 21,0 & 1 & 1,6 \\
\hline Que te den pocas alternativas de horarios & 29 & 46,8 & 11 & 17,7 & 21 & 33,9 & 1 & 1,6 \\
\hline Que el/la profesional no te explique bien lo que te pasa & 27 & 43,6 & 19 & 30,6 & 15 & 24,2 & 1 & 1,6 \\
\hline $\begin{array}{l}\text { Que te den horarios de atención en los que no puedas } \\
\text { asistir porque tenés otras actividades }\end{array}$ & 18 & 29,0 & 13 & 21,0 & 30 & 48,4 & 1 & 1,6 \\
\hline $\begin{array}{l}\text { Que el lugar en donde te tenés que atender quede muy } \\
\text { lejos }\end{array}$ & 16 & 25,8 & 8 & 12,9 & 36 & 58,1 & 2 & 3,2 \\
\hline No tener dinero para viajar & 9 & 14,5 & 21 & 33,9 & 31 & 50,0 & 1 & 1,6 \\
\hline
\end{tabular}

Fuente: Elaboración propia con base en el estudio de Rossi et al. ${ }^{(29)}$

organizacionales. En esta misma categoría mencionaron la falta de turnos, los "largos plazos con los que se da turno" y las "pocas alternativas de horarios". Entre las barreras culturales o simbólicas la dificultad principal para estas mujeres fue que el/la profesional no le explique bien lo que le pasa.

En consonancia, al indagar ¿qué hiciste para dejar de consumir (hayas tenido éxito o no)?, el acceso a respuestas más profesionalizadas del sistema formal de salud pareciera ser poco frecuente. Sobre las 61 mujeres, solo 5 reportaron que empezaron un tratamiento psiquiátrico o psicológico.

La Tabla 8 muestra las otras estrategias de atención de la salud que mencionaron las mujeres embarazadas y puérperas que se relacionaron mayormente con la autoatención. Entre las mujeres entrevistadas, 59 respondieron que asumieron una o más prácticas individuales de regulación del consumo: "decidí dejar de consumir", "dejé de comprar", "traté de reducir la cantidad", "abandoné el grupo de consumo", "intenté dejar y no obtuve el resultado esperado", "recurrí a la compañía de amigos", "me apoyé en mi pareja", "no advertí problemas en mi consumo". De modo no excluyente y en menor medida, 21 mujeres hicieron referencia por lo menos a una de las siguientes estrategias de
Tabla 8. Número y distribución porcentual de las respuestas de las mujeres embarazadas y puérperas entrevistadas ( $N=62)$, sobre estrategias adoptadas para dejar de consumir. Ciudades de Bariloche, Concordia y La Matanza, Argentina, 2018-2019.

\begin{tabular}{|c|c|c|}
\hline Estrategias para dejar de consumir & $\mathrm{n}$ & $\%$ \\
\hline \multicolumn{3}{|l|}{ Estrategias de regulación del consumo } \\
\hline Decidí dejar de consumir & 48 & 78,7 \\
\hline Dejé de comprar & 38 & 62,3 \\
\hline Traté de reducir la cantidad & 34 & 55,7 \\
\hline Abandoné el grupo de consumo & 15 & 24,6 \\
\hline $\begin{array}{l}\text { Intenté dejar, pero no obtuve el resultado } \\
\text { esperado }\end{array}$ & 15 & 24,6 \\
\hline $\begin{array}{l}\text { Recurrí a la compañía de mis amigos para } \\
\text { distraerme }\end{array}$ & 5 & 8,2 \\
\hline Me apoyé en mi pareja & 5 & 8,2 \\
\hline No advertí problemas en mi consumo & 5 & 8,2 \\
\hline \multicolumn{3}{|l|}{ Estrategias de sustitución del consumo } \\
\hline Usé cigarrillo electrónico & 3 & 4,9 \\
\hline Usé medicación & 3 & 4,9 \\
\hline Comía algo cuando me daban ganas de consumir & 20 & 32,8 \\
\hline \multicolumn{3}{|l|}{$\begin{array}{l}\text { Relacionado con algún evento vital o preocupación } \\
\text { de terceros }\end{array}$} \\
\hline Dejé por motivos de salud & 11 & 18,0 \\
\hline Dejé por pedido de un familiar & 7 & 11,5 \\
\hline \multicolumn{3}{|l|}{ Consulta a un "especialista" } \\
\hline Me apoyé en la Iglesia & 10 & 16,4 \\
\hline Empecé tratamiento psiquiátrico o psicológico & 5 & 8,2 \\
\hline Otras & 1 & 1,6 \\
\hline
\end{tabular}

Fuente: Elaboración propia. 
autoatención que involucraban la sustitución del consumo: "comía algo cuando me daban ganas de consumir", "usé medicación", "usé cigarrillo electrónico".

En 8 casos, las mujeres relacionaron el cese del consumo con algún evento vital como el embarazo y la preocupación de terceros ("dejé por pedido de un familiar", "dejé por motivos de salud"):

Sé que hace mal fumar durante el embarazo. Los paquetes de cigarrillos lo dicen. Cuando es para una cuesta más, pero cuando estás a cargo de otra vida es diferente. (26 años, embarazada, Bariloche)

Pensé que el consumo podía matar a mi bebé... es una droga fea... (18 años, puérpera, Concordia)

Me lo pidió mi vieja y sentí que, si no dejaba la droga, ella se iba a morir por verme así. (20 años, embarazada, La Matanza)

A partir de estos datos se puede inferir que, en ocasiones, la principal motivación para abandonar el propio consumo es el hecho de asumirse responsables del cuidado de sus hijas e hijos por nacer o las personas cercanas.

\section{DISCUSIONES}

En el estudio que motiva este artículo también se pudo observar, en una muestra acotada de 62 mujeres de tres ciudades, la transformación de los patrones de consumo a la que aluden las investigaciones mencionadas en la introducción.

Los datos sobre consumo de sustancias mostraron que, tanto para los consumos durante la vida como para aquellos que ocurrieron en los últimos tres meses y durante el embarazo, las mayores frecuencias se dieron en relación con el uso de tabaco y de alcohol. También se relevó que, en muchas ocasiones, abandonar o disminuir el propio consumo durante el embarazo, para las mujeres constituye una forma de cuidar a sus hijos/hijas por nacer o a personas cercanas, ubicándose así ellas mismas como encargadas de brindar cuidados, más que como sujetos con derecho al cuidado.

Otro aspecto notorio es la existencia de un fuerte vínculo entre el consumo de sustancias por parte de las mujeres y de quienes conviven con ellas, mostrando con ello que cuando las mujeres mantenían algún tipo de vínculo sexo-afectivo con un varón, sus propios consumos se adaptaban a los de sus compañeros. Esto resulta similar a lo encontrado en otro estudio con 150 usuarios de cocaína $^{(42)}$ que hizo visible cómo la sustancia se establece como un modo de comunicación o de identificación en la pareja.

Respecto de los niveles de apoyo social, se observó que algunas entrevistadas, pese a referir que siempre o la mayoría de las veces contaban con apoyo, finalmente no recurrían a esas personas para compartir sus temores o problemas más íntimos, y que el apoyo disminuía especialmente en la distribución de las tareas domésticas y de cuidado. En este punto cabe interrogar, desde el concepto de economía del cuidado $^{(43)}$, la dimensión real de los apoyos y las redes con que cuentan estas mujeres y cuánto de cierto ideal social referido a los roles de género las lleva a responder que sí cuentan con alguien que les muestra amor y afecto o con alguien a quien amar y sentirse queridas y no mencionan los mismos niveles de apoyo cuando se refieren a alguien que las ayude en sus tareas domésticas si están enfermas o alguien que las lleve al médico cuando lo necesiten, sin lograr problematizar la posible contradicción entre ambos tipos de respuestas.

En consonancia, el bajo puntaje obtenido para el ítem apoyo material puede ser comprendido a la luz de los datos arrojados por la Tercera Encuesta Factores de Riesgo ${ }^{(40)}$ de trabajo no remunerado y uso del tiempo. Esta encuesta mostró que existen algunas condiciones que extienden el tiempo que la mujer dedica al trabajo no remunerado de cuidado, entre las que aparecen: estar en edad productiva (de 18 a 64 años), ser cónyuges, tener hi- 
jos/as menores de 6 años en el hogar y habitar en hogares con bajo nivel de ingreso, características que priman en la muestra.

Por lo tanto, el uso del tiempo de las mujeres está condicionado por el imperativo de ejercer tareas de cuidado, lo que las aleja -entre otras cosas- de la posibilidad de asistir a las instituciones de salud cuando se trata de cuidarse a sí mismas. Paralelamente, sostener el trabajo no remunerado es posible para ellas siempre y cuando reduzcan los tiempos de cuidado propio, de descanso y de esparcimiento, lo cual repercute negativamente en la calidad de vida de las mujeres, constituyéndose en un indicador más de inequidad de género.

Con relación a las representaciones que las mujeres otorgan a sus consumos de sustancias, algunas entrevistadas refirieron preocupación por las consecuencias del uso de sustancias en el embarazo, otras lo significaron como un modo de evadir los problemas de su realidad cotidiana, y varias mencionaron la diversión y el placer. Cabe aquí entonces preguntarse acerca de la omisión de la dimensión del placer asociada a los usos de drogas, tanto en los estudios académicos como en la construcción de estadísticas. Esto podría interpretarse como una operatoria de poder, un dispositivo de disciplinamiento funcional a la consolidación de los mandatos de género que, al mismo tiempo, homologa unívocamente droga a problema. Los estudios sobre consumos de sustancias psicoactivas en mujeres embarazadas y/o madres ${ }^{(44)}$ solo retoman esta dimensión invisibilizada, y hacen foco en las hijas y los hijos de esas mujeres, asumiendo que si una usuaria de sustancias psicoactivas antepone su propio placer no puede hacerse responsable de otra persona. Desde esa posición se delimitan discursos de culpa y miedo que asocian el uso de drogas únicamente con formas dependientes ${ }^{(45)}$.

También reproducen representaciones sociales estigmatizantes acerca de las usuarias y los usuarios de drogas, identificándose con imágenes sociales que connotan juicios de valor negativos sobre las mujeres que, siendo madres, consumen sustancias psicoactivas y rompen con los mandatos como mujer y madre. En consonancia, refieren haberse sentido discriminadas en diferentes ámbitos y por diversos motivos, no solo por la situación socioeconómica, la edad y la raza, sino también por cuestiones específicas asociadas al género -como el hecho de ser usuarias de drogas embarazadas o puérperas- por las que en ocasiones se han sentido rechazadas y humilladas. Sin embargo, lo que esto refleja podría denominarse discriminación interseccional, aquella que se ve magnificada por opresiones múltiples que agravan su situación de vulnerabilidad: ser mujeres, ser indígenas y/o migrantes, usar drogas y ser pobres.

Por otro lado, la discriminación en los servicios de salud puede resultar de la posición simbólica que los agentes de salud ocupan en el microcosmos del campo médico $^{(46)}$, es decir de las asimetrías de poder que se establecen, dentro del sistema de salud, entre las y los profesionales de la salud y las usuarias. En particular, en este ámbito, se mencionaron situaciones de violencia obstétrica frecuentemente invisibilizadas, es decir, aquellos tratos deshumanizados y abusos de medicalización que ejerce el personal de salud sobre el cuerpo y los procesos reproductivos de las mujeres ${ }^{(47)}$. Abundan relatos sobre este tipo de dificultades, que suelen ser naturalizados pero que, al mismo tiempo, alejan a las mujeres de los servicios de salud para la atención oportuna e informada en el embarazo y el parto. Estos cruces de tipos de violencia y problemas de consumo desde una perspectiva de género evidencian un área de vacancia en el estado del arte.

Las dificultades de estas mujeres para acceder a los servicios de salud radican en el hecho de que se alejan del modelo androcéntrico a partir del cual el sistema de salud está diseñado. Sin embargo, estas barreras tradicionalmente son interpretadas desde los efectores de salud como "escaso compromiso terapéutico" por parte de las mujeres, como si se tratara solo de una decisión individual. Al no incorporar en el abordaje las especificidades de esta población, la otra deviene en una extraña peligrosa y la asimetría subjetiva en los vínculos profesional de la salud-usuaria favorece a la cosificación y 
objetalización de esta población. Se tornan "objetos de atención" y desde ese lugar simbólico se implementan abordajes ligados a la "buena o mala predisposición" de las y los profesionales que intervienen.

La contrapartida es la preeminencia de otras estrategias de atención de la salud por parte de las mujeres, poco frecuentes en la bibliografía sobre el tema, vinculadas a la autoatención $^{(47)}$ tanto a través de modificaciones en la regulación individual como colectiva de las prácticas de consumo. En algunos casos, como relevamos en otros estudios ${ }^{(48,49)}$, los cambios en la regulación de las prácticas se deben a la irrupción de eventos vitales.

\section{CONCLUSIONES}

Diferentes resultados abrevan en un mismo atravesamiento: cómo las expectativas vinculadas al rol de género sitúan y estructuran de algún modo las particularidades de las diferentes situaciones que atraviesan las mujeres entrevistadas.

En este sentido, el rechazo hacia las mujeres que usan drogas durante el embarazo parto y puerperio podría pensarse como un analizador a través del cual se expresa la idealización y las exigencias acerca de la maternidad que recaen sobre las mujeres. Si la subjetividad de las mujeres está socialmente constituida a partir de alcanzar la maternidad como proyecto de vida, la culpa y la estigmatización es su contracara y pareciera manifestarse al alejarse de estos modelos.

Las múltiples violencias -tanto de género como raciales y obstétricas- a las que están expuestas las mujeres usuarias de drogas, se intersectan y multiplican. Como resultado, las inequidades en salud relacionadas con el género afectan desproporcionadamente a las mujeres pobres, jóvenes y de minorías étnicas. En este sentido, ser mujer, madre y usuaria de sustancias supone múltiples posiciones de subordinación social a partir de las cuales las barreras culturales o simbólicas se agravan.

De este modo, las expectativas asociadas al rol de género y la falta de tratamientos que consideren su posición social, las condiciona al ocultamiento del propio consumo y al despliegue de estrategias de autoatención. Al mismo tiempo, la estigmatización posiblemente genere escaso reconocimiento de una serie de regulaciones individuales y colectivas de cuidados y el ocultamiento del consumo que, a su vez, impide visibilizar los procesos de discriminación.

Los efectores de salud, con sus prácticas, pueden profundizar o revertir las inequidades que experimentan las mujeres en el acceso a la atención. Por ello, en lo que respecta a los programas de abordaje de los consumos problemáticos, resulta urgente incluir la perspectiva de la reducción de riesgos y daños. Es necesario que los equipos de salud reconozcan que los consumos admiten múltiples modalidades que resultan de la trama situacional que se entreteje entre sujetos-contextos-sustancias.

Finalmente, cabe recalcar que este estudio busca aportar a la producción de evidencias que permitan a los efectores de salud abordar la problemática desde la perspectiva de la complejidad, entendiendo que brindar acompañamiento de calidad para las mujeres-madres-usuarias de drogas requiere comprender los problemas específicos que enfrentan. Solo a través de este reconocimiento, los equipos de salud podrán acompañar a las mujeres en la construcción de alternativas que les permitan decidir acerca de sus propios consumos sin tener que renunciar por ello a su salud ni a sus hijos e hijas. 


\section{AGRADECIMIENTOS}

En particular a los aportes y lecturas de Diana Rossi, Yamila Abal, Gonzalo Ralón y Graciela Touzé. A Gabriela Olivera por sugerirnos y facilitarnos materiales acerca de la temática de estudio. A quienes facilitaron el acceso a la muestra: Leonardo Gil, Germán Guaresti, Fernando Tortosa, Daniela Goye, Sara La Spina, Gastón Vera, Carmen Anguita, Felipe de Rosa, Víctor Parodi, Natalia Kertz, Marcos Clausen, Gabriela Letón, Juan Rendo, Susana López Anido, Patricia Franco, Oscar Di Marco, Paula Allan, Carla Padovani, Alejandra Schneebeli, Patricia Fernández, Susana Tomasini, Paula Barberis, Fernanda Ganuza, Victoria Sánchez, Sandra Blasquiz, Miriam Ávila, Lucía Suárez, Betina Biscayart, María Pía Flores, Alfonso Zuñiga, Juan Manuel Cristiani, Lorena Sagaut, Gabriela Roth, Fernanda Díaz, Paula Hofer, Abel Butto, Eugenia Castellano, Julieta Ovin, Melina Quevedo, Celeste Avancini, Javier González y Valeria Hafford. A los comités de ética intervinientes: Comisión Municipal de Bioética de La Matanza (COMUBI), Comisión Conjunta de Investigaciones en Salud de la provincia de Buenos Aires (CCIS), Comité de Ética del Hospital Dr. Ramón Carrillo de Bariloche, Comisión Provincial de Evaluación de Proyectos de Investigación en Salud Humana de Río Negro (CEEPISH) y Comité de Bioética de Entre Ríos. A los Servicios del Hospital Zonal Bariloche: Obstetricia, Ginecología, Clínica Médica, Servicio Social, Pediatría, Salud Mental, Departamento de Actividades Programadas para el Área, Enfermería, residencias de Clínica Médica y Medicina General. Al Municipio de San Carlos de Bariloche y en particular a la Secretaría de Desarrollo Humano Integral, a la Subsecretaría de Coordinación de Políticas Sociales, a la Dirección de Instituciones y al Departamento de Género. Al Sistema de Abordaje Territorial del Consejo Provincial de la Mujer, Delegación Zona Andina (provincia de Río Negro). Agradecemos, además, el financiamiento de este estudio a través de las becas de Salud Investiga de la Dirección de Investigación del Ministerio de Salud y Desarrollo Social de la Nación.

\section{REFERENCIAS BIBLIOGRÁFICAS}

1. Oficina de las Naciones Unidas contra la Droga y el Delito. Informe mundial sobre las drogas: Resumen, conclusiones y consecuencias en materia de políticas [Internet]. 2018 [citado 10 mar 2019]. Disponible en: https://tinyurl.com/ya5nbr4b.

2. Comisión Interamericana para el Control del Abuso de Drogas, Organización de los Estados Americanos. Informe sobre el consumo de drogas en las Américas [Internet]. 2019 [citado 10 mar 2019]. Disponible en: https://tinyurl.com/yywye9g7.

3. Secretaría de Políticas Integrales sobre Drogas de la Nación Argentina. Estudio nacional en población de 12 a 65 años, sobre consumo de sustancias psicoactivas: Informe de resultados No. 1 [Internet]. 2017 [citado 10 mar 2019]. Disponible en: https://tinyurl.com/y42dfxjr.

4. Althabe F, Colomar M, Gibbons L, Belizán J, Buekens P. Tabaquismo durante el embarazo en Argentina $y$ Uruguay. Medicina. 2008;68(1):48-54.
5. Lichtenberger A, López M, Cremonte M. Intervención breve para promover la abstinencia de consumo de alcohol en mujeres gestantes: Una reflexión crítica. PSIENCIA, Revista Latinoamericana de Ciencia Psicológica. 2015;7:428-437. doi: 10.5872/psiencia/7.3.122.

6. López MB, Arán Filippetti V, Cremonte M. Consumo de alcohol antes y durante la gestación en Argentina: prevalencia y factores de riesgo. Revista Panamericana de Salud Pública. 2015;37(4/5):211-217.

7. Secretaría de Políticas Integrales sobre Drogas de la Nación Argentina. El uso indebido de drogas y la consulta de emergencia, quinto estudio nacional: Informe final de resultados Argentina 2012 [Internet]. Presidencia de la Nación; 2013 [citado 10 mar 2019]. Disponible en: https://tinyurl.com/y45lwl6n.

8. Tajer D, Reid GB, Lo Russo A, Cuadra ME, Jeifetz V, Roitenburd F, Ceneri E, Solis M, Salvo I. Equidad de género en la calidad de atención en adolescencia. Anuario de Investigaciones. 2015;22:301-308.

9. Rengel D. La construcción social del otro: Estigma, prejuicio e identidad en drogodependientes y enfermos de sida. Gazeta de Antropología. 2005;21:1-14

10. Touzé G, (org.). Saberes y prácticas sobre drogas: el caso de la pasta base de cocaína. Buenos Aires: Intercambios AC, FIUC; 2006

11. Allport G. The nature of prejudice. Massachusetts: Wesley Publishing; 1979

12. Quiles MN, Morera MD. El estigma social: la diferencia que nos hace inferiores. En: Morales JF, Huici C, Gómez A, Gaviria E, (coords.). Método, teoría e investigación en psicología social. Madrid: Pearson Prentice Hall; 2008. p. 377-399.

13. Romo-Avilés N, Camarotti AC. Haciendo género en un mundo de varones: el consumo de pasta base de cocaína entre las mujeres de la Ciudad de Buenos Aires. La Aljaba segunda época. 2015;(19):229-235.

14. Fernández AM. La mujer de la ilusión: Pactos y contratos entre hombres y mujeres. Buenos Aires: Paidós; 1993.

15. Zaldúa G, Sopransi MB, Longo R. Vulnerabilidad, género y prácticas de autonomía. En: Zaldúa G, Bottinelli $M$, (comps.). Praxis psicosocial comunitaria en Salud: Campos epistémicos y prácticas participativas. Buenos Aires: EUDEBA; 2010.

16. Parga J. "Etnografía sobre la equidad de género en la atención del uso problemático de sustancias: un análisis sobre la "adherencia" al tratamiento". [Tesis de Maestría]. La Plata: Facultad Latinoamericana de Ciencias Sociales; 2012.

17. Llort Suárez A, Ferrando Esquerré S, Borrás Cabacés T, Purroy Aritzeta I. El doble estigma de la mujer consumidora de drogas: estudio cualitativo sobre un grupo de autoapoyo de mujeres con problemas de abuso de sustancias. Alternativas: Cuadernos de Trabajo Social. 2013;20:9-22. 
18. Tortosa Pl. Trayectorias de atención y cuidado en la salud de mujeres en situación de calle en la Ciudad Autónoma de Buenos Aires. [Tesis de Maestría]. Buenos Aires: Universidad Nacional de Lanús; 2015.

19. Romo Avilés N. La mirada del género en el abordaje de los usos y abusos de drogas. Revista Española de Drogodependencias. 2010;35(3):269-272.

20. Maffia D. El ocultamiento de las mujeres en el consumo de sustancias psicoactivas. Buenos Aires: Unidad de Seguimiento de Políticas Públicas en Adicciones, Legislatura de la Ciudad Autónoma de Buenos Aires; 2011.

21. Setién L, Parga J. Disciplinamientos y estrategias biopolíticas de control de los cuerpos de mujeres usuarias de sustancias psicoactivas. En: Horizontes en intervenciones sociales [Internet]. Buenos Aires: Teseo; 2018 [citado 10 mar 2020]. Disponible en: https://tinyurl.com/ y4onknuk.

22. Chodorow N. El ejercicio de la maternidad. Barcelona: Gedisa; 1984

23. Marcús J. Ser madre en los sectores populares: una aproximación al sentido que las mujeres le otorgan a la maternidad. Revista Argentina de Sociología. 2006;4(7):

24. Castilla V, Lorenzo G. Emociones en suspenso: maternidad y consumo de pasta base/paco en barrios marginales de Buenos Aires. Cuadernos de Antropología Social. 2012;(36):69-89.

25. Camarotti AC, Romo-Avilés N, Jiménez Bautista $F$. Vulnerabilidad y prácticas de cuidado en mujeres consumidoras de pasta base del área metropolitana de Buenos Aires. Acta Psiquiátrica y Psicológica de América Latina. 2016;62(2):96-107.

26. Touzé G. Prevención del consumo problemático de drogas: Un enfoque educativo. Buenos Aires: Ministerio de Educación, Troquel; 2016.

27. Menéndez E. De sujetos saberes y estructuras. Introducción al enfoque relacional en el estudio de la salud colectiva. Buenos Aires: Lugar Editorial; 2000.

28. Comes Y. Accesibilidad: Una revisión conceptual. Documento laboris del Proyecto de Investigación (UBACYT P077); 2004.

29. Rossi D, Pawlowicz MP, Zunino Singh D. Accesibilidad de los usuarios de drogas a los servicios públicos de salud en las ciudades de Bs. As. y Rosario: La perspectiva de los trabajadores de la salud. Buenos Aires: Intercambios AC, ONUDD; 2007.

30. Sanchez Pardo L, González B, Cid González P, Fernández Lamparte A, Morán Iglesias M, Platas Ferreiro J. Drogas y perspectiva de género: Documento marco. Galicia: Xunta de Galicia; 2011.

31. Lagarde M. Los cautiverios de las mujeres: madresposas, monjas, putas, presas y locas. México: UNAM; 2005.
32. Aranja X, Germán I. Las personas usuarias de drogas especialmente vulnerables y los derechos humanos: personas usuarias con patología dual y mujeres usuarias de drogas. Eguzkilore. 2005;(19):169-215.

33. Organización Mundial de la Salud. La prueba de detección de consumo de alcohol, tabaco y sustancias (ASSIST): Manual para uso en la atención primaria [Internet]. 2011 [citado 10 mar 2019]. Disponible en: https://tinyurl.com/y43rq776.

34. Organización Mundial de la Salud. Intervención breve vinculada a ASSIST para el consumo problemático de sustancias: Manual para uso en la atención primaria [Internet]. 2011 [citado 10 mar 2019]. Disponible en: https://tinyurl.com/y68vsmd4.

35. D'Angelo J, Hubez G, De Cesare MD, Pedro D, Farace $\mathrm{H}$. Estudio nacional sobre violencias contra la mujer: Basado en la International Violence Against Women Survey (IVAWS). Buenos Aires: Ministerio de Justicia y Derechos Humanos de la Nación; 2015.

36. Ware JE Jr, Sherbourne CD. The MOS 36-item shortform health survey (SF-36) (I): Conceptual framework and item selection. Medical Care. 1992;30(6):473-483.

37. Revilla L, Luna J, Bailón E, Medina I. Validación del cuestionario MOS de apoyo social en Atención Primaria. Medicina de Familia (And). 2005;10(6):10-18.

38. Rodríguez Espínola S, Enrique HC. Validación Argentina del Cuestionario MOS de Apoyo Social Percibido. Psicodebate, 2007;7:155-168. https://doi. org/10.18682/pd.v7i0.433

39. Instituto Nacional contra la Discriminación, la Xenofobia y el Racismo. Racismo. En: Hacia un plan nacional contra la discriminación: La discriminación en Argentina, Diagnóstico y propuestas. Buenos Aires: INADI; 2005. p 49-56.

40. Ministerio de Salud de la Nación, Instituto Nacional de Estadística y Censos. Tercera Encuesta Nacional de Factores de Riesgo para Enfermedades No Transmisibles. Buenos Aires: Ministerio de Salud; 2015.

41. Instituto Nacional de Estadística y Censos. Censo Nacional de Población, Hogares y Viviendas 2010. Buenos Aires: INDEC; 2010.

42. Rossi D, Pawlowicz MP, Cymerman P, Goltzman P, Touzé G. Evaluación rápida y desarrollo de respuestas en el uso de cocaína inhalable y la conducta de riesgo sexual en Buenos Aires 2002-2003: Informe Final Buenos Aires: Intercambios AC; 2003.

43. Rodríguez Enríquez C. Economía feminista y economía del cuidado: Aportes conceptuales para el estudio de la desigualdad. Nueva Sociedad. 2015;256:30-44.

44. Medina-Mora ME, Rojas GE. Mujer, pobreza y adicciones. Perinatología y Reproducción Humana. 2003;17 (4):230-244.

45. Goltzman P. Ideas poderosas: Producción de salud y cuidado en el uso de drogas con adolescentes. Buenos Aires: Intercambios AC; 2018. 
46. Gutiérrez A. Las tareas y compromisos del investigador social. En: Gutiérrez A. Política y poder. Buenos Aires: Eudeba; 2000. p 83-115.

47. Argentina. Ley 25929 [Internet]. 2004 [citado 10 mar 2019]. Disponible en: https://tinyurl.com/vzrgsnf.

48. Touzé G. Discursos, políticas y prácticas. En: Touzé G. Saberes y prácticas sobre drogas: El caso de la pasta base de cocaína. Buenos Aires: Intercambios AC, FIUC; 2006.

49. Rossi D, Rangugni V. Cambios en el uso inyectable de drogas en Buenos Aires (1998-2003). Buenos Aires: Intercambios AC, Ministerio de Salud y Ambiente de la Nación, ONUSIDA, ONUDD; 2004.

\section{FORMA DE CITAR}

Diez M, Pawlowicz MP, Vissicchio F, Amendolaro R, Barla JC, Muñiz A, Arrúa L. Entre la invisibilidad y el estigma: consumo de sustancias psicoactivas en mujeres embarazadas y puérperas de tres hospitales generales de Argentina. Salud Colectiva. 2020;16:e2509. doi: 10.18294/sc.2020.2509.

Recibido: 30 ago 2019| Versión final: 25 jul 2020 | Aprobado: 6 ago 2020 | Publicado en línea: 21 sep 2020

obra está bajo una licencia de Creative Commons Reconocimiento-NoComercial 4.0 Internacional. Reconocimiento - Permite copiar, distribuir y comunicar públicamente la obra. A cambio, se debe reconocer y citar al autor original. No Comercial - Esta obra no puede ser utilizada con finalidades comerciales, a menos que se obtenga el permiso. 